\title{
Projeto Ítaca: por um saber sobre drogas \\ a partir do campo educacional
}

\author{
Douglas Casarotto de Oliveira', Guilherme Carlos Côrrea² \\ I Integrante do Grupo Ítaca, Psicologo CAPS ad Cia do Recomeço. Coordenador da Escola de Redução de \\ Danos Ítaca. Esp. em Humanização da Gestão e Atenção do SUS (ESP-UFRGS), Mestre em Educação (UFSM), \\ Doutorando em Psicologia Social e Institucional (UFRGS). \\ E-mail: douglascasarotto@hotmail.com \\ 2 Integrante do Grupo Ítaca, Professor Adjunto do Centro de Educação da UFSM. Coordenador do LAMEN. \\ Lic. Quimica; Mestre em Educação (UFSC), Dr. Em Ciências Sociais (PUC-SP). \\ E-mail: gcarloscorrea@gmail.com
}

Recebido em: 14 jan. 2019. Aceito em: 03 mar. 2019. DOI: http://dx.doi.org/10.21674/2448-0479.52.160-169

\section{Resumo}

Este artigo trata de apresentar e problematizar a experiência do Projeto Ítaca Escola de Redução (ERD), onde tem sido possível desenvolver um processo de experimentação e invenção de uma perspectiva educacional sobre o campo das drogas que emerge dos saberes oriundos das práticas dos redutores de danos do Rio Grande do Sul. Para isso, realizou-se um recorte de tal experiência, que ocorreu entre os anos de 2013 e 2015 . Para a apresentação deste percurso, dois momentos foram traçados. Num primeiro, realizou-se uma genealogia do projeto Ítaca, apontando suas proveniências e momento de sua emergência num cenário de transição da Redução de Danos. Num segundo momento, a partir de um olhar cartográfico apresentamos alguns pontos de aprendizado a partir das práticas da ĺtaca ERD, apontando para um movimento de atualização da Redução de Danos (RD), a qual se dá a partir das pessoas envolvidas com a RD, na articulação da noção de RD com outros dispositivos do SUS e da reconfiguração da noção de campo.

Palavras chave: Redução de Danos. Educação. Saúde. Drogas.

\section{Abstract}

This article aim to present and problematize the experience of the Ithaca Project School of Harm Reduction (SHR), which has been possible to develop a process of experimentation and invention of an educational perspective on the field of drugs that emerges from the knowledge derived from the practice of harm reduction of the Rio Grande do Sul State/Brazil. For that, it was selected a clipping of this experience, which occurred between the years of 2013 and 20I5. For the presentation of this course, two moments were drawn. First, a genealogy of the Ithaca project, pointing out its origins and the moment of its emergence in a scenario of transition of Harm Reduction. In a second moment, from a cartographic view we present some learnings from the practices of Ithaca (SHR), showing a movement to actualization of the Harm Reduction (HR), which occurs from the people involved with the HR, in the articulation of the notion of HD with other SUS devices and the reconfiguration of field notion.

Keywords: Harm reduction. Education. Health. Drugs.

\section{Introdução}

Os processos hegemônicos em curso nas instituições de saúde, justiça e educação têm como base a noção proibicionista de drogas. Na área da saúde, tal noção se apresenta na perspectiva da abstinência, da 
supervalorização da substância em detrimento do sujeito que a utiliza e da percepção da pessoa que usa droga como doente. No campo da justiça, a noção proibicionista determina o enquadramento da pessoa que usa drogas como delinquente, havendo aplicação de penas que incluem a privação de liberdade. Já a área da educação reproduz as noções advindas da Saúde (doença) e da Justiça (crime), compartilhando com suas práticas e permitindo que os profissionais da área policial sejam, muitas vezes, os agentes pedagógicos no campo das drogas (OLIVEIRA, 2009).

Tal cenário alinha-se à estratégia de guerra às drogas (RODRIGUES, 2004) e evidencia a limitação das intervenções pedagógicas às perspectivas da criminalização, patologização e, consequentemente, à penalização e ao tratamento. Esse é o campo epistemológico hegemônico que caracteriza as práticas sobre drogas.

É na criação de outras perspectivas a esse campo epistemológico e no reconhecimento de uma potência à educação enquanto saber sobre drogas que tem se dado as práticas do Projeto Escola de Redução de Danos Ítaca, vinculado ao Centro de Atenção Psicossocial álcool e outras drogas (CAPS ad) Cia do Recomeço, a quais serão apresentadas neste artigo.

\section{Materiais e métodos}

Diante da tarefa de apresentarmos o Projeto Escola de Redução Ítaca enfatizando sua força produtiva, este relato de experiência não se limitará a uma descrição linear de uma história das práticas realizadas. Inspirada na perspectiva genealógica (FOUCAULT,2004), apresentaremos inicialmente algumas proveniências de sua constituição, atentando ao momento em que se torna possível e estratégica a emergência de um projeto de educação no campo das drogas. Nesta parte do texto, como materiais de analise forma utilizados produções diversas, tais como documentos relativos aos projetos e produções acadêmicas que versam sobre o mesmo. Num segundo momento, a partir de uma perspectiva cartográfica (ROLNIK, 2007) buscaremos transformar em linguagem os afetos produzidos ao longo da experiência de implementação do Projeto. Nesta parte do texto, a experiência apresentada foi registrada em diário de campo em duas formas: individual, produzido pelos autores e coletivo, produzido por todos os participantes. Para fins de definição dos aspectos a serem problematizados, elegemos cinco analisadores (BAREMBLITT, 20I2) os quais marcam as bifurcações que culminaram nos caminhos construídos ao longo desse processo.

\section{Resultados e Discussão}

\section{Um projeto sem origem}

Relatar a experiência da Escola de Redução de Danos Ítaca sem a pretensão de procurar um marco, uma origem, mas apresentar um campo de dispersão onde dar visibilidade a diversas linhas de força que permitem sua emergência. Essa é a tarefa desta primeira sessão. Para marcar o campo onde se produz a possibilidade de constituição da ERD Ítaca, destacamos três linhas: O programa de Redução de Danos de Santa Maria (PRD), o CAPS ad Cia do Recomeço e o Grupo Ítaca.

\section{A redução de danos no contexto da política de HIV-AIDS: O Programa de Redução de Danos (PRD) de Santa Maria}

Em Santa Maria, algumas ações em redução de danos foram realizadas pelo Consórcio Intermunicipal de Saúde nos anos de 2000 e 200 I. Entretanto, foi em 2002, com a implantação do Programa de Redução de Danos (PRD) sob gestão da Secretaria de Município da Saúde, que a redução de danos passou a ocupar espaço na política de saúde em âmbito municipal. Por meio do PRD, um conjunto de ações foi desenvolvido, incluindo um processo de educação permanente dos redutores de danos; seminários semestrais sobre drogas e redução de danos, voltados à comunidade e aos trabalhadores de saúde; atividades de formação permanente direcionadas a conselheiros municipais de saúde; dezesseis edições do Fórum Santamariense de Redução de Danos; projeto piloto de sistema de informação em RD, em parceria com a Secretária Estadual de Saúde SES/RS, projeto piloto de RD em Serviço de Atendimento Especializado (SAE HIV/aids), com a Política Nacional de de Doenças Sexualmente Transmissíveis-AIDS (PNDST/AIDS) do Ministério da Saúde 
e aprovação da Lei Municipal N $5 \mid 20$ de 20 de junho de 2008, que dispõe sobre a Redução de Danos no Município de Santa Maria e cria a Categoria Funcional de Agente Redutor de Danos à Saúde. Em relação à RD em Santa Maria, a aprovação da legislação instituindo o cargo de Redutor de Danos no munícipio foi tido como uma grande conquista, o que em tese garantiria essa função na rede de saúde do SUS de Santa Maria. (SILVA, 20I0) Contudo, no momento de aprovação desta lei o PRD, juntamente com outros serviços da Rede de Saúde de Santa Maria, encontravam-se fragilizado, com muitos dos profissionais de suas equipes sendo dispensados devido a sua contratação sem concurso público.

No ano de 2009, houve a demissão dos últimos redutores de danos da equipe do PRD (no momento contava com apenas dois redutores sendo que anos anteriores chegou a ter dez redutores de danos), que até então atuavam como contratados. Foi um momento onde o futuro das práticas da RD na cidade estava indefinido. Foi a partir da metade desse mesmo ano, que o CAPS ad Cia do Recomeço, iniciando a constituição de suas práticas, tentava afirmar o desafio de criar as práticas de RD num novo contexto, não mais vinculado à Política de HIV-AIDS, mas à política de Saúde Mental.

\section{A redução de danos na política de Saúde Mental: $O$ Centro de Atenção Psicossocial para usuário de álcool e outras drogas (CAPS ad) Cia do Recomeço}

Apesar de ser explicitamente citada na Política do Ministério da Saúde de atenção a usuários de álcool e outras drogas (BRASIL, 2003) como referencial teórico político para a atuação no cuidado de pessoas com problemas decorrentes do uso de álcool e outras drogas, operar a partir da lógica da Redução de Danos constitui-se como um desafio aos Centros de Atenção Psicossocial álcool e outras drogas, sendo que a tradição dos serviços que cuidam de pessoas que usam álcool e outras drogas é tomar como objetivo de sua clínica a abstinência às drogas (SOUZA, 2007, 2013).

Tendo como referenciais constitutivos de suas práticas algumas diretrizes da Política Nacional de Humanização do SUS (BRASIL, 2008) como o Acolhimento, a Clínica Ampliada e a Redução de Danos, foi a partir da tentativa de compreensão acerca das práticas concretas dos Redutores de Danos em seu trabalho do campo, que o CAPS ad Cia do Recomeço buscou a invenção de seus dispositivos, apostando no caráter indissociável entre a gestão do serviço, a atenção prestada e a formação de seus profissionais. (OLIVEIRA, 20I4).

Negando-se a assumir os referenciais hegemônicos (médico-psiquiátricos e jurídico- policiais) em suas práticas, valorizando o saber produzido a partir das práticas dos redutores de danos em campo e reconhecendo que havia escassa referência em como atuar no cotidiano de um CAPS ad a partir da Redução de Danos, o CAPS ad Cia do Recomeço passou a experimentar uma série de práticas atuando simultaneamente no âmbito do cuidado e da educação permanente. Dessa forma, se a partir do âmbito do cuidado a arena de trabalho era cada caso atendido e a necessidade de produção de cuidado no território acionando redes intersetoriais, foi no âmbito da educação permanente que o CAPS pode experimentar intervenções no âmbito educacional, buscando a construção de saberes relativos ao campo das drogas e seus usos. Sem colocar-se na posição de ter um saber a priori sobre o que é a Redução de Danos ou como se faz a RD, foi a partir de três iniciativas educacionais que o CAPS Cia do Recomeço pode construir uma consistência em sua forma de encarar o devir RD do CAPS: a primeira delas foi à constituição da equipe cujos processos são apresentados no artigo "Cia do Recomeço: a constituição de um Centro de Atenção Psicossocial Álcool e drogas e o caráter indissociável entre gestão, atenção e formação"(OLIVEIRA, 20I4); a segunda foi a partir da participação na elaboração e execução do Projeto Ítaca: redução de Danos como ferramenta para práticas intersetoriais, financiado pelo Ministério da Saúde e executado em parceria com a UFSM nos anos de 2009 e 20I I, o qual foi revisitado a partir da dissertação de mestrado "Projeto Ítaca: estratégias educacionais para a abordagem no campo das drogas" (PORAZZI, 20I4) e a terceira foi a participação na elaboração do projeto e coordenação da Escola de Redução de Danos Ítaca, também em parceria com a UFSM, o qual foi executado entre os anos de 2013 e 2015.

\section{Grupo Ítaca: aglutinando experiências, potencializando saberes}

Esta linha referente ao grupo Ítaca é inspirada na dissertação de uma de seus integrantes (PORAZZI, 20I4). O Grupo Ítaca pode ser tomado como uma resultante das forças que se combinaram em torno do 
PRD de Santa Maria, do CAPS ad Cia do Recomeço e do Laboratório de Metodologia do Ensino (LAMEN), do Centro de Educação da UFSM os quais tinham em comum a problematização das drogas e seus usos numa perspectiva não proibicionista. Na medida em que o grupo foi se constituindo, suas produções acadêmicas e suas práticas educacionais no campo das drogas foram produzindo um modo singular de abordagem do tema droga no campo da educação. Dentre as produções acadêmicas, destacamos as oficinas como estratégia educacional independente da escolarização (CORRÊA, 2000), projetos de iniciação científica (CORRÊA, 2005), artigos (OLIVEIRA E DIAS, 20I I; CORRÊA, 2002, 20I I; SILVA, 20I I), dissertações de mestrado (OLIVEIRA, 2009; SILVA, 20I0; PORAZZI, 20I4), e trabalhos finais de especialização e curso de aperfeiçoamento (MAGALHÃES, 2009; PORAZZI, 20I0).

Mas foi a partir do Projeto Ítaca: redução de danos como ferramenta para práticas intersetoriais, financiado pelo Ministério da Saúde (2009-20I I) que o grupo Ítaca pode se experimentar no campo educacional abordando o tema drogas e seus usos a partir da potência vislumbrada na prática dos redutores de danos.

O projeto Ítaca propôs um curso sobre o tema drogas a partir das perspectivas Redução de danos que operavam nas práticas dos redutores de danos do RS. O curso foi realizado em duas séries. A primeira série consistia em reunir trabalhadores em redução de danos do Rio Grande do Sul para estudar, problematizar e planejar estratégias pedagógicas em redução de danos, tendo destaque a socialização das perspectivas e formas de atuação dos grupos de RD, a avaliação do trabalho que desenvolvem e, ainda, a concepção e estruturação do curso a ser oferecido na segunda série.

Para compor o grupo que estaria na primeira série foram convidadas pessoas que tinham uma trajetória conhecida por algum componente do grupo ítaca a qual considerávamos que poderiam contribuir com suas experiências. Até mesmo pessoas sem experiência nenhuma em RD, mas que se mostravam ávidas em aprender sobre o tema e se diziam descontentes com as práticas mais tradicionais ligadas a abstinência como única forma de tratamento foram convidadas. Currículos ou em saberes legitimados pela academia não eram os critérios para ser convidado a participar do projeto, mas sim a vivências que cada um tinha construído ao longo da sua trajetória em redução de danos. O grupo se constituiu e passou a se encontrar mensalmente, durante dois dias, de agosto a novembro de 2010 . A primeira série do Projeto Ítaca atuava para a realização de dois objetivos: a formação de educadores em redução de danos (primeiro objetivo) que elaborariam uma proposta do curso que seria dado na segunda série (segundo objetivo).

Conforme Porazzi (2014 pp. 43-44) "era claro que todos os participantes da primeira série estavam muito felizes. Cada um trazia sua história e trajetória, e compartilhava com pessoas que tinham histórias semeIhantes. Eram pessoas mobilizadas com a RD, que entendiam de RD e que independente de onde estivessem iriam continuar trabalhando com RD. A redução de danos emergia como um estilo de vida e não apenas como uma função, o que mostrava a força destas práticas. E foi assim que foram formados os educadores e que se organizou o curso oferecido na segunda série."

A oferta do curso da segunda série do projeto tentou suprir a quase completa ausência de preocupação dos cursos universitários quanto à questão das drogas, sua complexidade e o cuidado de pessoas expostas à rede de narcotráfico. No dia dezenove de novembro de dois mil e dez teve início a segunda série do projeto Ítaca e o curso de formação Redução de Danos: Ferramenta para a Atuação no Campo das Drogas. Além do dia dezenove de novembro o curso teve mais seis encontros que aconteceram de março até maio de dois mil e onze. Essa segunda série do projeto foi destinada à, principalmente, estudantes universitários de áreas tais como saúde, comunicação social, direito e licenciaturas, mas foi aberta também a profissionais da área da saúde, da assistência, do judiciário e demais interessados.

O curso teve como principal público estudantes universitários, já que, havia uma questão norteadora do grupo Ítaca: Ao ingressarmos em um curso universitário temos, sem dúvida, uma compreensão sobre drogas. Com que compreensão saímos da Universidade e iniciamos a vida profissional?

Foi pensando nesta questão que se decidiu o público alvo, afinal são os estudantes das áreas citadas que irão trabalhar direta ou indiretamente com o tema drogas ou com pessoas que usam drogas. A constatação de que raramente os cursos universitários proporcionam a possibilidade de pensar e produzir conhecimento sobre o assunto potencializou a vontade do grupo de promover o curso que foi todo estruturado com os redutores de danos do estado durante os quatro encontros da primeira série do projeto Ítaca. A segunda série ofereceu a oportunidade dos redutores atuarem como educadores dentro de uma universidade. Sem a necessidade de ensinar, o curso foi pautado no compartilhamento de saberes. 
Com a apresentação dessas três linhas foi possível demarcar algumas forças que deram possibilidade de emergência da ERD Ítaca. A partir da experiência de quase 10 anos do PRD foi possível o desenvolvimento de práticas nos territórios a partir das noções mais clássicas da Redução de Danos, ligadas a política de HIV-AIDS. Além destas, o PRD possibilitou o início de uma articulação entre pessoas que já problematizavam as práticas tradicionais no campo das drogas, e que viam em seu cotidiano de atuação uma possibilidade de invenção de novas práticas. A partir do CAPS ad Cia do Recomeço, a Redução de Danos pode ser experimentada cotidianamente num campo árido, tomado pelas práticas de saúde tradicionais ligada ao campo das drogas, onde a noção de tratamento é referenciada à norma da abstinência. É nesse cenário onde a RD, articulada a diretrizes e dispositivos da Política Nacional de Humanização, passa a ser reinventada para dar conta dos objetivos de uma Reforma Psiquiátrica Antimanicomial, simultaneamente em nível de cuidado e de educação permanente. Enfim, é em torno do grupo Ítaca que as linhas anteriormente mencionadas passam a se conectar e a realizar produções teóricas sobre a RD como potência para a abordagem das drogas em âmbito educacional. Para além disso, o Grupo Ítaca torna-se o meio por onde uma educação sobre drogas fundamentada nas práticas dos redutores de danos se materializa e ultrapassa os "muros" dos serviços de Saúde, afirmando o caráter intersetorial necessário a uma abordagem do tema drogas. Em primeiro lugar o Projeto Ítaca legitima os saberes dos redutores de danos aprendidos em anos de experiência, formando-os educadores em RD. Em segundo, adentra nas formações acadêmicas de áreas não mais ligadas a saúde somente, mas aos campos da educação, comunicação social e direito.

\section{Cartografia de uma experiência intersetorial em educação sobre drogas - ERD Ítaca}

Num contexto construção de um trabalho no CAPS ad Cia do Recomeço e de execução do Projeto Ítaca, em meados de 2010 o Ministério da Saúde lança edital financiando Projetos de Escola de Redutores de Danos. Como a experiência do Grupo Ítaca já trazia a questão da educação e RD, a elaboração de um projeto para concorrer ao Edital não teve maiores problemas, pelo contrário, pode ser feita com a expectativa de dar consistência à proposta já realizada a partir do Projeto Ítaca. Aprovado em 2010, por dificuldades burocráticas a Escola de Redução de Danos Ítaca iniciou seu funcionamento apenas em setembro de 2013. É a partir do início de seu funcionamento de fato que esta cartografia será realizada. Sem ater-se a uma descrição cronológica de como funciona a ERD, nesta sessão serão apresentados cinco analisadores, que se tornam importantes para a compreensão do processo e, principalmente, para ilustrarmos alguns aprendizados operados nesse percurso. A partir daqui, o texto segue uma narrativa em primeira pessoa, onde mesclamos cenas, histórias e outros elementos que possam auxiliar a expressar essa experiência.

\section{De Escola de Redutores de Danos para Escola de Redução de Danos}

Como uma proposta inicial de formar 18 agentes redutores de danos, a ERD teve seu projeto readaptado em 20 I I, depois da I Oficina de Escolas de Redução de Danos, realizada em Brasília neste mesmo ano. A orientação geral que a nova coordenação de Saúde Mental deu para viabilizar os diferentes projetos aprovados em diversos municípios do país era a de que cada ERD deveria se adaptar a sua realidade, pois, para a coordenação nacional não havia necessidade de formar redutores de danos, já que não poderiam garantir a institucionalização desse profissional no SUS. A partir dessas orientações o projeto ERD Ítaca tomou um formato distinto. Não consistiria mais num curso de formação de agentes RD, mas em dois cursos: um de formação em Redução de Danos e outro de formação de Redutores de Danos. A formação em RD seria um curso direcionado para trabalhadores da Rede de Santa Maria, estudantes universitários, usuários dos serviços e interessados, com aulas ministradas pelos Educadores RD formados no Projeto Ítaca. Sua programação reeditou a proposta original do Projeto Ítaca, com os ajustes necessários realizados por cada Educador em RD. 


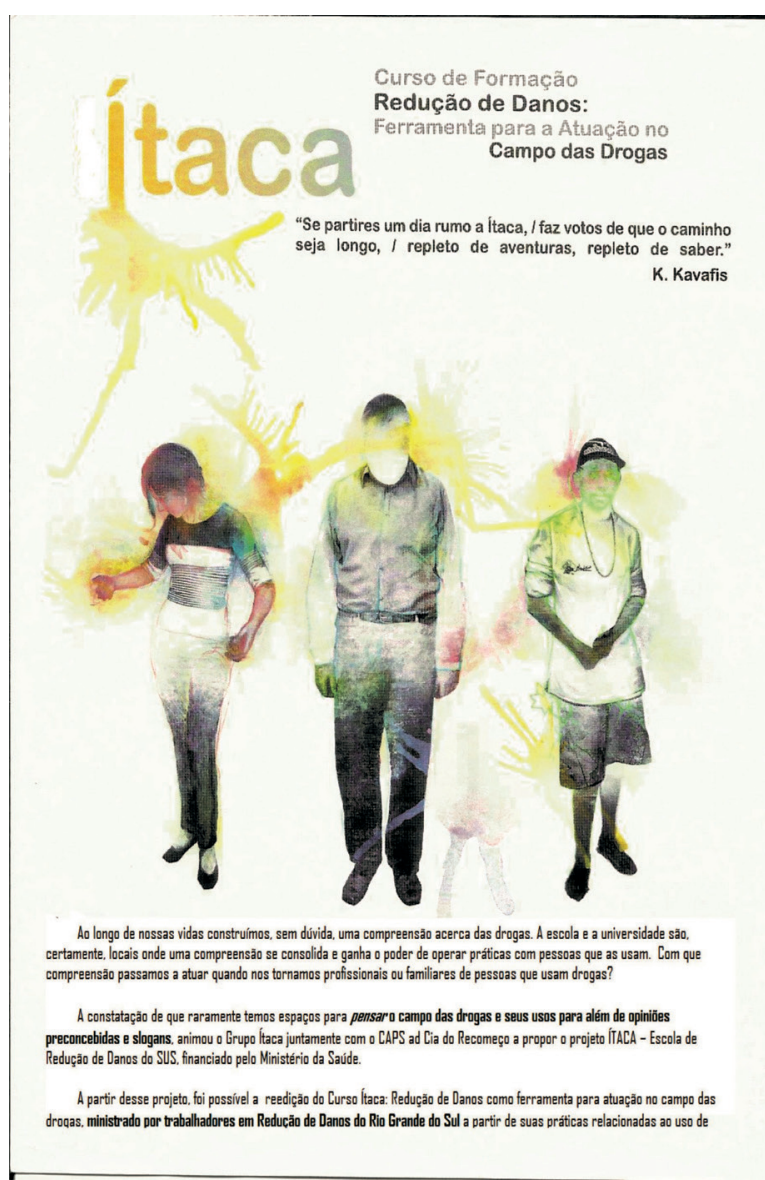

CURSO ÍTACA: Redução de Danos como Ferramenta para a atuação no campo das drogas PROGRAMAÇÃo

Dia 22/11/13 - das 14:00 às 18:00, no auditório MULTIUSO da UFSM (ao lado da reitoria) Abertura do curso - Representantes do Ministério da Saúde, das Secretarias Estadual e Municipal de Saúde e UFSM

ítaca - Escola de Redução de Danos do SUS - Coordenaçãa do projeto Drogas e Educạão-Guilherme Carlos Corrêa

Dia 29/11/13 - das 14:00 às 18:00, no auditório da Prefeitura Municipal de Santa Maria (junto ao prédio da prefeitura na Rua Venâncio Aires)

Redução de Danos: Práticas e Ferramentas - Silvia Borges e Elisandra Vieira Duas máquinas: vic como falta e vida como excesso - Guilherme Corrêa e Fávia Costa da Silva

Dia 06/12/13 - das 14:00 às 18:00, no auditório da Prefeitura Municipal de Santa Maria (junto ao prédio da prefeitura na Rua Venâncio Aires)

Reduço de Danos Itinerante - Martha Souza Casarotto de Oliveira e Juliane Heinrich

Dia 13/12/13 - das 14:00 às 18:00, no auditório da Prefeitura Municipal de Santa Maria (junto ao prédio da prefeiturana Rua Venâncio Aires)

Arteiros (eles vão crescer) - Carlos Guarnieri e Éderson Edenir Ferreira

Redução de Danos enquanto perspectiva de trabalho - Maria Luiza Diello e Leonardo Kozoroski

Dia 20/11/13 das $14: 00$ às 18:00, no auditório da Prefeitura Municipal de Santa Maria (junto ao prédio da prefeitura na Rua Venâncio Aires)

ReDes cuidar, acolther e a poiar - Elissandra Siqueira e Moisés Romanini

Pontos de encontro e zonas de trocas - Michele Eichelberger e Eliz andro Farias

CARGA HORÁRIA: 20 horas, certificadas pela UFSM - VAGAS LIMIT ADAS

Informações:

E-mail: çursoitaca@gmail.com

Fone: CAPS ad Cia do Recomeço - 39211099

Inscrições GRATUIT AS pelo link:

https://docs.google.com/forms/d/1Ys7ebnEhot 3QFOHnOjrht yu9nNwFwRC-VmhtcirTwl/viewform

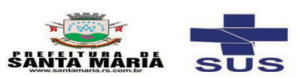
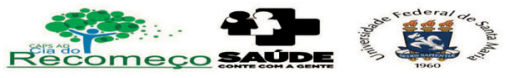

Figura I De Escola de Redutores de Danos para Escola de Redução de Danos.

Já a formação de Redutores de danos, segunda série, era a novidade da ERD. É aqui que focamos os últimos analisadores.

\section{Composição do grupo}

Incumbidos de realizar uma formação de Redutores de Danos, uma pequena, mas importante questão emergiu na equipe de coordenação: quem selecionar? Após algumas conversas passamos a considerar: que o edital mencionava em formar "nativos", no sentido de abrir espaço para pessoas que atuassem nos territórios; que no Ítaca anterior o critério de convite para a formação como Educador em RD se deu a partir do conhecimento que tínhamos acerca da trajetória dos convidados. Mesmo sem muita certeza, passamos a listar nomes de pessoas que considerávamos importante de participar da ERD. Sua importância se dava por considerar que a participação na ERD poderia potencializar algumas práticas que já realizavam. Os nomes também eram de pessoas que considerávamos que já tinham uma atuação afim da RD, mesmo que não nomeasse dessa forma sua prática. Assim, chegamos numa turma muito heterogênea, com potência de atuação em diferentes âmbitos, para além da saúde. O estudante de publicidade trabalhava no CAPS CIA do Recomeço em um projeto de extensão há dois anos, coordenando uma oficina audiovisual. Do Coletivo de Resistência Artística Periférica (CO RAP), coletivo que realiza diversas intervenções na cidade a partir do movimento hip hop, foram cinco convidados. Além destes, um enfermeiro residente do CAPS Cia do Recomeço também foi convidado, muito em função da "naturalidade" com que se propunha a realizar atividades nos territórios. Um acadêmico da psicologia que realizava estágio numa Unidade de Estratégia de Saúde da Família da cidade, o qual entramos em contato a partir da prática de apoio matricial. Em sua prática, esse acadêmico mostrava uma sensibilidade ao território que considerávamos similar a dos redutores de danos que conhecíamos. Um homem que atua como militante no campo do HIV-AIDS, que participa há anos na cena de Santa Maria em espaços de controle social, na construção de práticas de protagonismo das pessoas que vivem com HIV. Uma acadêmica de biomedicina, a qual desenvolvia trabalhos com o público LGBT. Enfim, os quatro Redutores de Danos concursados de Santa Maria, os quais entraram para o cargo sem qualificação para exercer essa função. 
No convite a essas pessoas, marcamos uma reunião para falar da proposta. Ver o interesse das mesmas à oferta que fazíamos já indicava que a seleção havia sido acertada. Situação que se confirmou ao longo do curso. Se no momento de escolher que participaria da turma os critérios não eram tão claro, ao longo da ERD percebemos que, para além das qualidades racionalmente pensadas acerca de cada um, foi um critério sensível que os ligava aos redutores de danos que conhecemos no Projeto Ítaca, que determinou essa escolha.

\section{Apoiador em Redução de Danos - uma formação estratégica}

Definida a turma, em outra reunião de coordenação realizávamos uma discussão a partir da seguinte questão: formaríamos Redutores de Danos? Lembramos da Oficina de Escolas de Redução de Danos, onde foi mencionada por gestores do MS que a figura do Redutor de Danos não era prioridade e diante do cenário' (ano de 20l I), pensamos: como fazer uma formação que possa abrir espaço para que esse pessoal possa circular como trabalhadores nas redes intersetoriais, seja na saúde, na assistência social, na cultura? Foi aí que ponderamos que, no contexto do SUS, uma tecnologia denominada função apoio (OLIVEIRA, 20I I) estava em alta, ou seja, estava sendo bastante difundida tanto nos meios acadêmicos como nos serviços, como uma tecnologia que auxilia as equipes a ampliarem sua capacidade de análise e, consequentemente, de intervenção. A partir dessa discussão decidimos que era estratégico proporcionar uma formação que lhes desse condições de atuar como apoiadores e como redutores de danos. Definimos que a ERD Ítaca estaria formando, então, apoiadores em RD. Nessa formação, além da atuação como Redutores de Danos, eles deveriam construir conhecimentos e se apropriarem de tecnologias que os possibilitasse apoiar as equipes com quem trabalhassem.

\section{Movimentando a noção de campo}

Este analisador apresenta a reconstrução da noção de campo em RD ao longo do percurso da RD. Se inicialmente identificávamos o campo da RD como aquele relativo aos territórios frequentados por usuários, principalmente as cenas de uso, com a medida em que íamos acessando o que entendíamos como campo, essa noção se modificava para dar conta da proposta de formação de apoiadores em RD.

Após a parte "teórica" (participação na formação em Redução de Danos que era aberta também para a rede), foi acordado que a partir de janeiro de 2014 passaríamos a realizar a formação em campo. Dia 10 nos encontramos e nos dividimos em quatro miniequipes para fazer campo. Os territórios tomados como campo foram definidos tendo como critérios o vínculo já construído com a equipe de atenção básica e com a comunidade a partir do trabalho realizado pelo CAPS ad Cia do Recomeço e também pela análise da relação dos apoiadores com cada território. Cada nova equipe foi composta por três apoiadores em formação e um educador em RD.

No trabalho de campo nos territórios houve com uma certa facilidade em acessar as pessoas. Inicialmente houve uma visita às equipes das Unidades de Saúde de cada local para apresentar a proposta da ERD. E em seguida houve as saídas a campo, onde distribuímos insumos tais como preservativos, materiais educativos relativos a ISTs, AIDS e saúde mental. A partir dessa distribuição buscávamos conhecer as demandas da comunidade. Contudo, depois de três semanas no campo, sentimos que abordar a comunidade e conhecer suas demandas não era suficiente. Percebemos que além de identificar as demandas tínhamos que, minimamente, conhecer os serviços e políticas que poderiam dar conta das mesmas. Foi aí que tivemos que redefinir a estratégia de saídas a campo, e com isso redesenhar esse conceito e a própria formação.

A partir dessa demanda de formação - conhecer serviços e políticas intersetoriais - alteramos o campo a ser realizado. Somando-se aos territórios, passamos a tomar os Serviços da rede como uma parte importante do campo a ser trabalhado pelo apoiador em RD. Assim, as miniequipes foram colocadas "em suspenso" e entre todos, passamos a realizar visitas a diferentes serviços da Rede de Santa Maria: CAPS ad Caminhos do Sol, CAPS i O Equilibrista, CAPS II Prado Veppo, Secretaria de Desenvolvimento Social, Conselho Tutelar Centro, Conselho Municipal de Entorpecentes (COMEN), Secretaria Municipal de Saúde, Casa de Passagem.

\footnotetext{
' Era um cenário onde a figura do Redutor de Danos tradicional, ligados a práticas preventivas ao HIV junto a usuários de drogas injetáveis, perdia espaço no SUS em função da migração das pessoas que usavam cocaína injetada para cocaína fumada (crack). 
As visitas a esses pontos da Rede aconteciam também nas sextas à tarde. Além de conhecer cada serviço, sua finalidade, suas dificuldades e potencias, esse campo foi fundamental para a aprendizagem sobre a função apoio. A partir de cada visita realizada o grupo exercitava sua forma escuta, sua reação ao que escutava, sua forma de intervir, de questionar, a maneira de apresentar-se e apresentar a ERD. Tal exercício permitiu uma associação entre o fazer do Redutor de Danos e o fazer do Apoiador.

Se para atuar como redutores de danos tínhamos como pressuposto que precisávamos realizar uma escuta e intervenção: que evitasse julgamentos morais; que tirasse o foco da substância; que auxiliasse na compreensão das demandas singulares de cada pessoa ou comunidade; que apostasse no potencial das pessoas; que estimulasse seu protagonismo e corresponsabilização, que não fossem prescritivas, passamos a entender que, como apoiadores, esses pressupostos também poderiam ser úteis. Afinal, ao acessar equipes de trabaIhadores com as mais diversas formas de pensar sobre o tema drogas e seus usos, com diferentes demandas e interesses, seria contraditório assumir posições distintas daquelas que considerávamos importantes para o trabalho nos territórios como Redutor de Danos. Apesar de discutirmos essa questão, nas visitas era muito difícil aos apoiadores, por exemplo, escutar posições preconceituosas em relação ao tema drogas e não querer logo intervir e mostrar como era a visão da Redução de Danos. Assim, cada visita servia como experimentação ao grupo, que em cada reunião posterior avaliava e discutia o que foi escutado e as intervenções realizadas.

Ao final desse campo realizado nos serviços da rede havíamos aprendido que, além dos pressupostos aprendidos com o trabalho de campo dos redutores de danos, o apoiador em RD, nos Serviços da Rede, deveria desenvolver a capacidade de não atuar de forma reativa às posições mais preconceituosas em relação ao tema drogas e seus usos, mas sim, a partir de um vínculo com a equipe apoiada, encontrar espaços para construir suas intervenções conjuntamente com a mesma, de forma que, como efeito dessa intervenção, a equipe consiga ampliar sua forma de compreender as questões relativas ao cuidado de pessoas que usam drogas.

Por fim a dissolução da noção de campo tradicional em RD, identificado ao território, pode ser acolhida no percurso do grupo. Tal acolhimento serviu para que pudéssemos dar um sentido ao que será o campo de atuação do apoiador em RD.

\section{De volta aos territórios - das comunidades de Santa Maria ao Rio Grande do Sul}

Após dois meses de visitas aos territórios, de visitas a diferentes pontos da rede, nas reuniões do grupo redefinimos as últimas práticas da ERD. Voltaríamos aos territórios, contudo com outra estratégia, atualizada pelo que havíamos construído acerca do trabalho do apoiador em RD. Nossa nova proposta era produzir vínculo com as ESFs escolhidas para, junto com essas equipes, irmos até a população. Foi o momento em que pensávamos que a função apoiador em RD poderia tomar contornos mais específicos. Era o momento em que a ida ao território e a ida as equipes de saúde se encontrariam na mesma ação. Novamente foram definidos grupos para as idas as ESFs. Nesse novo arranjo formamos três grupos. A partir de cada experiência nos campos pode-se realizar diferentes aprendizados. Até mesmo numa equipe em que não foi possível desenvolver atividades, pode-se aprender sobre apoio. A história dessa intervenção é a seguinte.

Numa visita inicial, após ter marcado com a enfermeira da equipe, chegamos lá e fomos recebidos pelo médico, que nos atendeu brevemente, mas enfatizou que não havia sido informado que iriamos lá. $\mathrm{Na}$ semana seguinte, conversamos com a enfermeira via telefone e a mesma desculpou-se e disse que gostaria de nosso trabalho. Nessa semana fomos até a equipe, conversamos com a enfermeira e outros integrantes sobre a nossa proposta, e agendamos para a semana seguinte. Na semana seguinte novamente a enfermeira não estava na unidade, e também os Agentes Comunitários de Saúde não haviam sido avisados para estarem lá como o combinado na reunião anterior. Após tais desencontros, o sentimento que circulava entre o grupo era de que a equipe estava desinteressada, que estava tratando o grupo com descaso, entre outros. Apesar de não negarmos esses sentimentos, fizemos o exercício de tentar escutar o que a equipe estava nos dizendo com esses desencontros. Chegamos à conclusão que a equipe não estava preparada a esse apoio, mas não conseguia expressar de outra forma e que de dada adiantaria culpabilizar a equipe pela não realização do apoio. Dias depois, conversando com profissionais da equipe em outro contexto, soubemos que a equipe estava passando uma situação difícil, onde um ACS estava sendo afastado por suspeita de tráfico de drogas, e outros trabalhadores estavam sendo ameaçados, o que confirmou nossa hipótese de que a equipe não estava com condições de receber o apoio que estávamos ofertando. 
Apesar de termos definido que o final da ERD seria nos territórios, apoiando as equipes de ESF, um atravessamento aconteceu na formação, foi acolhido pelo grupo e serviu para dar consistência à prática do Apoiador. A partir de abril de 2014 passamos a ser convidados para falar sobre a ERD e ministrar oficinas sobre o tema conforme nossa experiência. A primeira delas foi no I Encontro Estadual sobre Protagonismo de Usuários da Saúde Mental. Foi um encontro de dois dias em que o grupo pode conviver mais tempo junto, bem como ministrar sua primeira oficina sobre o tema. Em seguida a ERD passou a ser convidada para os Encontros Macrorregionais da RD, tendo participado de 4 deles em mesas redondas, oficinas e apresentações culturais e em um deles (realizado em Santa Maria) como organizadores.

Novamente, acolher os convites para realização de mesas e oficinas serviu como campo de experimentação do "apoiar em RD", tendo em vista que, em sua maioria, o objetivo dos eventos era sensibilizar as redes regionais para as questões sobre o uso de álcool e outras drogas apresentadas a partir da RD. Para além do exercício de realizar oficinas, de falar sobre o que faziam como apoiadores em RD, esta participação serviu para dar consistência à formação, a qual se deu a partir do estabelecimento de diferentes redes entre apoiadores e outras pessoas que trabalham com RD no país e também do reconhecimento e valorização do trabalho do grupo realizado no âmbito da ERD.

\section{Considerações finais}

\section{Ítaca não produz escola, mas movimento}

Ao relatar a experiência da ERD Ítaca foi possível retomar não só o percurso deste projeto, mas de um grupo chamado Ítaca e suas produções. Ao finalizar o projeto ERD, a sensação era de que algo estava faltando, de que precisávamos mais alguns meses, anos para saber mesmo o que fazer como redutores de danos, como apoiadores em Redução de Danos. Impressão que foi relatada por vários dos apoiadores formados pela escola. Contudo, ao buscar um distanciamento desse sentimento e uma compreensão dos efeitos desse projeto em nós e nos que com ele se envolveram, chegamos a algumas considerações provisórias sobre a educação sobre drogas operada a parir de Ítaca. Uma delas é que não há uma noção de RD a ser preservada. O que se tem feito em Ítaca é colocar em movimento essa noção e dar-lhe consistência a partir das práticas concretas cotidianas, seja dos agentes redutores de danos, seja dos apoiadores em RD, ou de qualquer pessoa que se disponibilize a colocar em movimento seu pensamento em relação ao tema drogas e seus usos. Uma segunda consideração é a de que a partir de Ítaca não se produz uma nova verdade sobre drogas e seus usos, mas se coloca em questão as verdades tomadas como absolutas e se aposta nas verdades construídas a partir da singularidade dos encontros, os quais são capazes de indicar a trama envolvida em cada situação envolvendo drogas e seus usos. Enfim, uma terceira e última consideração é que Ítaca não se preocupa em fazer escola, em criar uma linha de Redução de Danos para que as pessoas possam se filiar e realizar suas práticas. Ítaca produz busca, movimento. As pessoas que eventualmente se encontraram em Ítaca saem com ferramentas, indicações, direções. São convidadas a, em sua singularidade, encontrar a maneira como no seu dia a dia, nos diferentes âmbitos de sua vida, poderão utilizar essas ferramentas para construir novas possibilidades de atuação em relação às drogas e seus usos.

\section{Referências}

BAREMBLITT, Gregório. Compêndio de análise institucional e outras correntes: teoria e prática. 6 ed. Belo Horizonte: Instituto Felix Guattari, 2012.

BRASIL. A política do Ministério da Saúde para Atenção Integral a Usuários de Álcool e Outras Drogas. Brasília, 2003.

Ministério da Saúde. Humanizasus: política nacional de humanização: documento base para gestores e trabalhadores do SUS. 4. ed. Brasília, 2008.

CORRÊA, Guilherme Carlos. Oficina: novos territórios em educação. In: PEY, Maria Oly. Pedagogia Libertária - experiências hoje. São Paulo: Imaginário, 2000.

“Escola-droga”. Verve, São Paulo, Nu-Sol/PEPG-Ciências Sociais PUC SP, n. I, 2002. 
O cuidado com a verdade: drogas e educação para além do bem e do mal. Programa de Licenciaturas-PROLICEN, 2005.

. Drogas para além do bem e do mal; In: SANTOS, Loiva M. (org) Outras palavras sobre o cuidado de pessoas que usam drogas. Porto Alegre: RS Conselho Regional de Psicologia do Rio Grande do Sul, 2005.

FOUCAULT, Michel. Microfísica do Poder. 19. ed. São Paulo: Graal, 2004.

MAGAlHÃES. Cláudia V. E. A Potencialização da Clínica Ampliada na Política HIV/AIDS/Programa Redução

de Danos. (monografia de especialização) Humanização da Atenção e Gestão do SUS, 2009.

OLIVEIRA, Douglas C. Uma genealogia do jovem usuário de crack: mídia, justiça, saúde, educação. UFSM/Santa Maria, 2009 (Dissertação de Mestrado) Programa de Pós-graduação em Educação de Universidade Federal de Santa Maria (UFSM) para obtenção do título mestre em educação), 2009.

; DIAS, Mariana H. Os jovens usuários de crack e a rede de cuidados: problematizações a partir de uma experiência; In: SANTOS, Loiva M. (org) Outras palavras sobre o cuidado de pessoas que usam drogas. Porto Alegre/ RS Conselho Regional de Psicologia do Rio Grande do Sul, 2014.

; VAN DER SAND. A.; MORCELLI. A; HEINRICH. J. Cia do Recomeço: a constituição de um Centro de Atenção Psicossocial e a indissociabilidade entre gestão, atenção e formação. In: PINHEIRO, R; SILVA, F; LOPES, T; SILVA JUNIOR, A. Experenci(ações) e práticas de apoio no SUS: integralidade, áreas programáticas e democracia institucional. LAPPIS, 2014.

OLIVEIRA, Gustavo N. Devir apoiador: uma cartografia da função apoio. Tese (Doutorado) - Universidade Estadual de Campinas, Faculdade de Ciências Médicas. Unicamp, $201 \mathrm{I}$

PORAZZI, Alexandra R. A História de um Acompanhamento Terapêutico, trabalho final da 5. ed. Curso de Acompanhamento Terapêutico promovido pela Escola de Saúde Pública do Rio Grande do Sul, 2010. Projeto Ítaca: estratégias educacionais para a abordagem da questão das drogas. UFSMISanta Maria (Dissertação de Mestrado) Programa de Pós-graduação em Educação da Universidade Federal de Santa Maria (UFSM) para obtenção do título de mestre em educação, 2014 .

ROLNIK, Suely. Cartografia Sentimental. Transformações Contemporâneas do Desejo. Porto Alegre: Sulina; Editora da UFRGS, 2007.

SILVA, Flávia Costa. Redução de Danos: campo de possibilidades para práticas não proibicionistas em saúde. In: SANTOS, Loiva M. (org). Outras palavras sobre o cuidado de pessoas que usam drogas. Porto Alegre: Conselho Regional de Psicologia do Rio Grande do Sul, 201 I.

Percurso da noção de drogas em educação: por uma problematização do proibicionismo. UFSM/Santa Maria (Dissertação de Mestrado) Programa de Pós-graduação em Educação de Universidade Federal de Santa Maria (UFSM) para obtenção do título mestre em educação), 2010.

SOUZA, Tadeu. P. Redução de danos no Brasil: a clínica e o movimento. Dissertação (Mestrado em Psicologia) Programa de Pós-Graduação em Psicologia, UFF, Niterói, 2007.

. A Norma da Abstinência e o Dispositivo “drogas”: Direitos universais em territórios marginais de produção de saúde (perspectivas de redução de danos. Tese (Doutorado em Saúde Coletiva) - Pós-graduação em Saúde Coletiva do Departamento de Saúde Coletiva da Faculdade de Ciências Médicas, UNICAMP, Campinas 20I3. 